\title{
Spatiotemporal Spread of Abnormal Vertical Growth of Macadamia in Australia Informs Epidemiology
}

\author{
Mohamed C. M. Zakeel, ${ }^{1,2, \dagger}$ Andrew D. W. Geering, ${ }^{1}$ and Olufemi A. Akinsanmi ${ }^{1, \dagger}$ \\ ${ }^{1}$ The University of Queensland, Queensland Alliance for Agriculture and Food Innovation, Centre for Horticultural Science, GPO Box 267, \\ Brisbane 4001, Australia \\ ${ }^{2}$ Department of Plant Sciences, Faculty of Agriculture, Rajarata University of Sri Lanka, Puliyankulama, Anuradhapura, Sri Lanka \\ Accepted for publication 20 March 2020.
}

\begin{abstract}
Australian macadamia production is threatened by a disorder known as abnormal vertical growth (AVG), for which the etiology is unknown. AVG is characterized by vigorous upright growth and reduced lateral branching, flowering, and nut set that results in over $70 \%$ yield loss annually. Six commercial macadamia orchards were surveyed in 2012 and again in 2018 to examine spatiotemporal dynamics of the epidemic. Data were subjected to point-pattern and geostatistical analyses. AVG incidence in all orchards showed a better fit to the beta-binomial distribution than the binomial distribution. AVG incidence in the different orchards varied between 5 and 47\% in 2012, and 13 and 55\% in 2018 and the rate of spread was slow, averaging at about $2 \%$ increase in disease incidence per annum. Spatial patterns of AVG were highly aggregated on both survey years and spread was mainly between neighboring trees in a
\end{abstract}

ABSTRACT row or trees that were opposite to each other in different rows. Semivariograms showed large range values (approximately 15 to 120 ), indicating aggregation of AVG-affected trees beyond quadrat levels. Furthermore, clusters of disease were mainly at the edge of the orchard on the first survey date and the disease progressed toward the center of the orchard over time. It is concluded that AVG is caused by an infectious agent, and based on patterns of spread, we hypothesize that spread is facilitated by root grafting or root-to-root contact. Furthermore, a vascular-limited pathogen could be involved that modulates plant hormone production.

Keywords: analytical and theoretical plant pathology, ecology and epidemiology, geostatistical analysis, Proteaceae, temporal dynamics, tree nut
Macadamia is a recently domesticated evergreen tree nut crop that is grown for its high value edible kernel in frost-free subtropical and tropical regions worldwide (Hamilton et al. 1983; Wallace and Walton 2011). Most commercial macadamia cultivars are Macadamia integrifolia or hybrids with $M$. tetraphylla. Both species are indigenous to southeastern Australia. Macadamia kernels can be eaten raw or roasted, processed into oil, or used as ingredients in confectionaries (Wallace and Walton 2011). Nutritional benefits of the kernels include high levels of monounsaturated fatty acids and a significant quantity of palmitoleic acid, which contribute to reducing serum triglycerides and low-density lipoprotein cholesterol (Garg et al. 2007; Griel et al. 2008). The demand for macadamia has significantly increased across all markets, and land area under commercial macadamia production is increasing worldwide (Wallace and Walton 2011).

Although there was limited commercial production of macadamia in Australia in the late 19th Century, the industry really began in earnest in Hawaii in the 1920s using seedling stock of M. integrifolia that was taken in the early 1880 s from wild trees at Mooloo and Mount Bauple in southeast Queensland (Hamilton et al. 1983; Nock et al. 2019; Stephenson 2005). Elite trees were then selected in Hawaii for clonal propagation and these cultivars were brought back to Australia. These Hawaiian selections form the foundation of the Australian industry and are also popular in other countries including South Africa, China, Kenya, Brazil, Guatemala,

${ }^{\dagger}$ Corresponding authors: M. C. M. Zakeel; m.mohamedzakeel@uqconnect.edu.au, and O. A. Akinsanmi; o.akinsanmi@uq.edu.au

Funding: Support provided by Macadamia Fund of Hort Innovation Projects MC16018 and MC15011 is acknowledged.

The author(s) declare no conflict of interest.

(C) 2020 The American Phytopathological Society and Vietnam (Hamilton et al. 1983; Stephenson 2005). In addition to these Hawaiian cultivars, a number of Australian cultivars are now commercially grown in several macadamia-producing countries (Peace et al. 2017).

Macadamia productivity is limited by many biotic agents including major oomycete and fungal pathogens such as Phytophthora cinnamomi (Akinsanmi et al. 2017), Diaporthe species (Akinsanmi and Drenth 2017), and Pseudocercospora macadamiae (Beilharz et al. 2003), and insect pests such as Cryptophlebia ombrodelta (Jones 1994), Hypothenemus obscurus (Jones et al. 1996), and Nezara viridula (Jones et al. 2001). In addition, Australian macadamia production is seriously threatened by a syndrome known as abnormal vertical growth (AVG). AVGaffected macadamia trees exhibit typical symptoms of excessive upright growth, fewer side shoots and flower buds and reduced nut set (Fig. 1) (O'Farrell 2011; O'Farrell et al. 2016). The root structure mirrors that of the branches, with the roots extending horizontally for $1 \mathrm{~m}$ before turning downward (O'Farrell et al. 2016). Severely affected orchards show a yield reduction of over $70 \%$, depending on the cultivar (Akinsanmi 2017). AVG causes an annual yield loss of over 2,000 metric tons of nuts in shell, which is equivalent to an annual loss of more than $\$ 10$ million to the Australian macadamia industry (Akinsanmi 2017). Hawaiian cultivars are highly susceptible to AVG, whereas most of the Australian cultivars are free of symptoms with no noticeable yield decline (Akinsanmi 2017; O'Farrell et al. 2016).

The occurrence of AVG was first reported in the mid-1990s from an area in the central Queensland region but by 2010, the syndrome was observed in all five major commercial production regions in Queensland and in a few areas in New South Wales (O'Farrell 2011). The number of AVG-affected trees in 2003 was estimated at between 18,000 and 22,000 (O'Farrell and Searle 2003). A survey in 2016 reported that AVG-affected orchards comprised more than 700 ha of land in Queensland and New South Wales, representing a fivefold increase in the number of symptomatic trees since 2003 
(Akinsanmi 2017). The symptoms were also reported from trees in urban residential areas (O'Farrell 2011). In most cases, about 15 to $50 \%$ of trees in affected orchards are currently AVG-symptomatic despite previous extensive removal of over $30 \%$ of severely affected trees (Akinsanmi 2017).

The cause of AVG is not known and its epidemiology is poorly understood. Elevated levels of t-ZR (a cytokinin hormone) in xylem sap and a gibberellic acid $\left(\mathrm{GA}_{3}\right)$ in apical buds of AVGsymptomatic trees have been detected, possibly enhancing the upright growth observed in AVG-affected trees (Fletcher and Mader 2007). Furthermore, lateral buds of AVG-symptomatic trees have shown significantly increased levels of abscisic acids (ABA), suggesting possible inhibition of lateral growth in AVG-affected trees (Fletcher and Mader 2007, 2011). Hormonal imbalance observed in AVG-symptomatic trees and a preliminary nextgeneration sequencing analysis of AVG-affected macadamia tree (M. Webb and A. Geering, unpublished data) have suggested possible biotic causes for AVG. However, these studies were limited to a few AVG-affected trees. No pathogenic soil nematodes or edaphic factors have been associated with AVG trees (O'Farrell and
Searle 2003). AVG was found on soils with varying physical and chemical properties, but no differences were observed in these properties at AVG and non-AVG sites (O'Farrell 2011; Stephenson et al. 2004), suggesting noninvolvement of any soil physical and chemical properties in AVG. A survey in 2006 showed the occurrence of AVG on Atherton Tableland, Queensland and northern New South Wales, which suggested the association of AVG with warm dry climates (O'Farrell 2011). However, the amount of sunlight received by the canopy has no bearing on the occurrence of AVG as symptomatic and nonsymptomatic trees coexist in the same orchards under the same light conditions. Soil moisture stress was suggested as a contributing factor that triggers the AVG syndrome (Akinsanmi 2017).

Spatiotemporal analyses of AVG incidence patterns may provide clues as to sources of inoculum and mode of spread, and thus indicate whether the cause is biotic or abiotic in nature (Gottwald et al. 1996). A preliminary study using the general SADIE (spatial analysis by distance indices) approach in three orchards in 2004 and 2006 suggested aggregated patterns of AVG in the affected orchards (O'Farrell 2011). However, since the reports of AVG

\section{A}

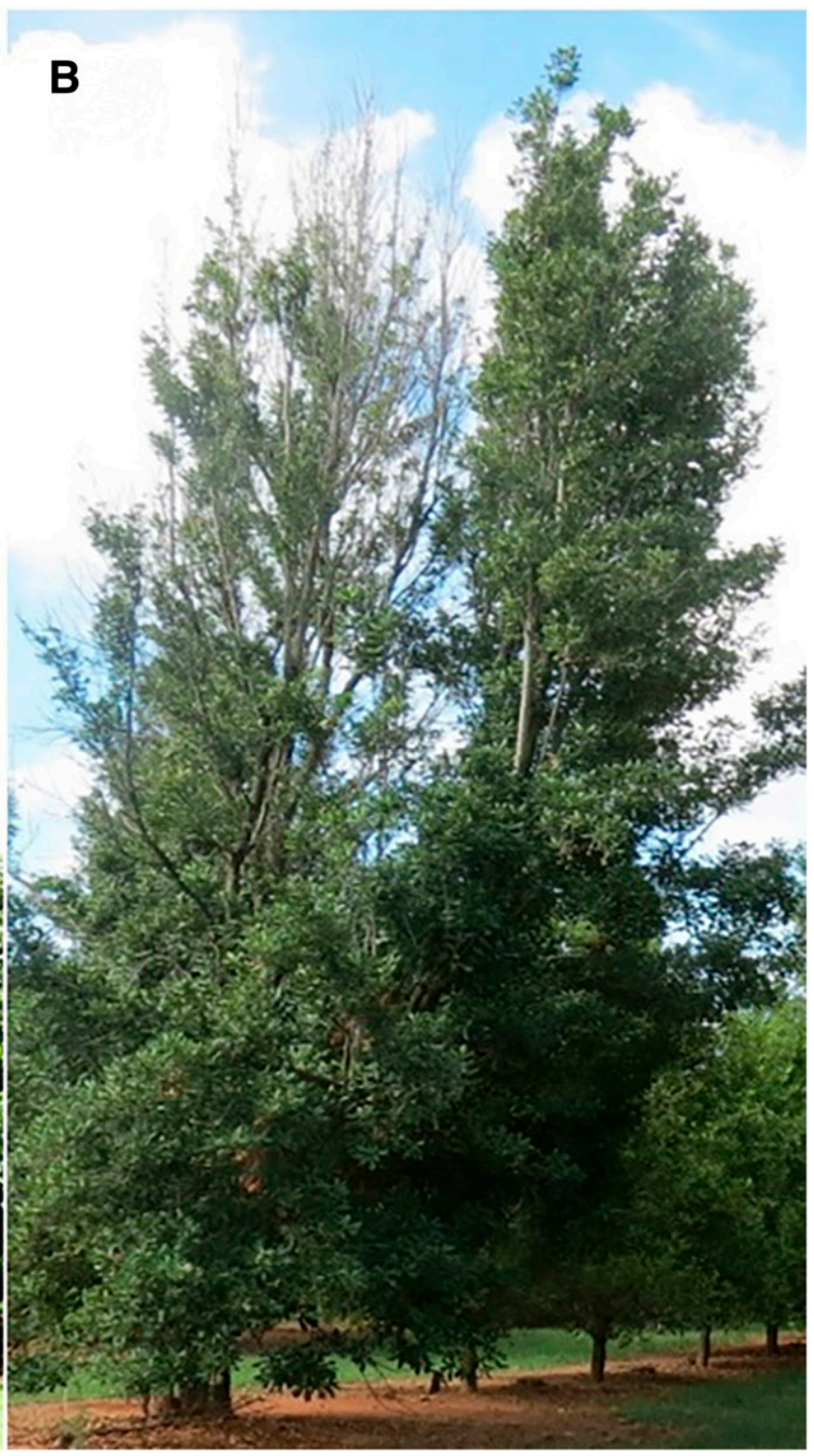

Fig. 1. Comparative canopy architecture of $\mathbf{A}$, a healthy tree with ovate canopy and $\mathbf{B}$, an abnormal vertical growth-affected tree showing vigorous upright growth with reduced lateral branching. 
incidence in several commercial orchards across the southeast Australia have increased (Akinsanmi 2017), it is unclear if the increase in the extent of area affected (spatial) or the increase in the number of AVG-affected trees over time (temporal) shows random or aggregated patterns. We hypothesized that AVG is due to an infectious agent and spreads from infected trees to others within close proximity in the orchard. This study investigated the incidence and spatiotemporal dynamics of AVG trees in six major commercial macadamia orchards in Australia over a 6-year interval.

\section{MATERIALS AND METHODS}

Data collection. Surveys for AVG were done in 2012 and 2018 in five commercial orchards in Bundaberg, Queensland $\left(24.8670^{\circ} \mathrm{S}\right.$, $152.3510^{\circ} \mathrm{E}$ ) and one in the Jiggi area, New South Wales $\left(28.7042^{\circ} \mathrm{S}, 153.1855^{\circ} \mathrm{E}\right)$ (Table 1$)$. All orchards had an average tree density of 312 trees/ha with a tree spacing of $8 \mathrm{~m} \times 4 \mathrm{~m}$. Depending on orchard dimensions, different quadrat sizes were used to include the maximum number of trees per orchard. While appropriate for the analysis of the dataset, these methods were constrained by the particular size of the quadrat used. In each quadrat, every tree was assessed for AVG symptoms, either presence (1) or absence (0).

Mapping of AVG incidence. Column and row numbers of each tree were used as $x$ - and $y$-coordinates, respectively. The tree spacing was used to determine the georeferenced coordinates of each tree in the plots. All spatial and statistical analyses were performed using the software package EPIPHY (version 0.3.4) in the $\mathrm{R}$ software environment unless otherwise indicated (Gigot 2018; R Development Core Team 2013). Visual mapping of spatial and temporal spread of AVG in each orchard was performed using heat maps of AVG patterns. Quadrat level incidence maps were produced for orchards representing different quadrat sizes with total number of quadrats $>500$.

Spatial patterns of AVG distribution. In order to determine if AVG-symptomatic trees are randomly distributed or aggregated in the orchard, binomial and beta-binomial distributions were fitted to the AVG incidence data for each orchard (Hughes and Madden 1993; Madden and Hughes 1995). Best fits were tested based on a $\chi^{2}$ goodness-of-fit comparison at $5 \%$ confidence interval and a loglikelihood ratio test statistic (LRS) (Gigot et al. 2017; Turechek et al. 2001). The significantly fitted data of beta-binomial distributions were used to estimate the beta-binomial parameters, including the expected probability of trees with AVG $(p)$ and the measure of heterogeneity in incidence data $(\theta)$ using simple maximum likelihood estimation (Gigot et al. 2017; Mak 1988; Turechek and Madden 1999a; Turechek and Mahaffee 2004). The intracluster correlation coefficient $(\rho)$, which is a measure of the similarity in AVG status of individuals within quadrats, was calculated using the following equation:

$$
\rho=\theta /(\theta+1)
$$

The $\rho$ value varies between 0 and 1 and a small $\rho$ value is indicative of larger within cluster variance compared with between cluster variance (Mak 1988). Response variability within a cluster reduces when individuals of a cluster show similarity among them (Mak 1988).

The Fisher's index of dispersion $(D)$ for AVG incidence was calculated separately for each orchard in both years. The ratio of the observed variance quantified from the proportions of individual AVG tree $\left(s_{o b s}^{2}\right)$ to the theoretical variance expected under binomial distribution $\left(s_{\text {bin }}^{2}\right)$ was used as the measure of $D$ as indicated in the following equation:

$$
D=s_{o b s}^{2} / s_{\text {bin }}^{2}
$$

thus, a value of $D<1$ indicates a uniform pattern, $D=1$ indicates a random pattern, and $D>1$ indicates an aggregated pattern at quadrat level (Madden and Hughes 1995). The significance of $D$ was tested using one-sample z-tests. The relationship between $\theta$ and $D$ was analyzed using the values of three orchards with similar quadrat size of $2 \times 2$ (Table 1 ). The observed AVG incidence was plotted against the Fisher's index $D$.

Degree of heterogeneity of AVG incidence. A binary version of Taylor's power law was used to evaluate the degree of heterogeneity in the AVG incidence data of the five large orchards with >60 total quadrats (Table 1). Data in both years for each orchard were combined for the analysis. Combinations of quadrats were used to generate larger orchard-level quadrat sizes to execute the power law analysis. The larger orchard-level quadrat sizes that produced nonzero observed variance were retained for the analysis (Table 2). Orchard 6 failed to produce nonzero observed variance with any possible larger orchard-level quadrat size and therefore was excluded from the power law analysis, but the larger orchardlevel quadrat size was retained for subsequent analyses. The

TABLE 2. Effective sample sizes of spatial hierarchy relationship between tree and quadrat levels for determining abnormal vertical growth incidence in commercial macadamia orchards surveyed using different numbers of trees per quadrat

\begin{tabular}{lccc}
\hline & & \multicolumn{2}{c}{ Effective sample size $(\hat{v})$} \\
\cline { 3 - 4 } Orchard & Orchard-level quadrat size & 2012 & 2018 \\
\hline Orchard 1 & $8 \times 8$ & $3.11 \pm 0.165$ & $2.97 \pm 0.228$ \\
Orchard 2 & $4 \times 3$ & $2.23 \pm 0.190$ & $2.15 \pm 0.228$ \\
Orchard 3 & $7 \times 10$ & $4.21 \pm 0.327$ & $4.04 \pm 0.384$ \\
Orchard 4 & $2 \times 5$ & $5.22 \pm 1.181$ & $4.83 \pm 1.401$ \\
Orchard 5 & $7 \times 25$ & $3.22 \pm 0.130$ & $3.09 \pm 0.184$ \\
Orchard 6 & $3 \times 5$ & $5.49 \pm 0.908$ & $5.76 \pm 1.213$ \\
\hline
\end{tabular}

TABLE 1. Details and one sample z-test of aggregation indices of six commercial macadamia orchards surveyed for abnormal vertical growth (AVG) symptoms in

\begin{tabular}{|c|c|c|c|c|c|c|c|c|c|c|c|}
\hline \multirow[b]{3}{*}{ Orchard } & \multirow[b]{3}{*}{ Production region $^{\mathrm{a}}$} & \multirow[b]{3}{*}{ Area (ha) } & \multicolumn{3}{|c|}{ Number of trees } & \multirow[b]{3}{*}{ Quadrat size ${ }^{b}$} & \multirow{3}{*}{$\begin{array}{c}\text { Total number of } \\
\text { quadrats }\end{array}$} & \multirow{2}{*}{\multicolumn{2}{|c|}{$\begin{array}{l}\text { Observed AVG } \\
\text { incidence }(\%)\end{array}$}} & \multirow{2}{*}{\multicolumn{2}{|c|}{$\mathrm{z}$ value $^{\mathrm{c}}$}} \\
\hline & & & & Columns & Rows & & & & & & \\
\hline & & & Total & $(x$-coordinate $)$ & $(y$-coordinate $)$ & & & 2012 & 2018 & 2012 & 2018 \\
\hline Orchard 1 & Bundaberg & 7.38 & 2304 & 48 & 48 & $2 \times 2(4)$ & 576 & 4.86 & 14.11 & 21.32 & 20.72 \\
\hline Orchard 2 & Bundaberg & 1.54 & 480 & 16 & 30 & $2 \times 2(4)$ & 120 & 46.67 & 54.58 & 16.64 & 14.34 \\
\hline Orchard 3 & Bundaberg & 14.36 & 4480 & 28 & 160 & $2 \times 4(8)$ & 560 & 5.25 & 13.17 & 32.49 & 42.53 \\
\hline Orchard 4 & Bundaberg & 4.21 & 1312 & 8 & 164 & $2 \times 8(16)$ & 82 & 19.59 & 31.48 & 43.02 & 51.12 \\
\hline Orchard 5 & Bundaberg & 8.97 & 2800 & 28 & 100 & $2 \times 2(4)$ & 700 & 5.14 & 14.11 & 14.33 & 15.88 \\
\hline Orchard 6 & Jiggi & 1.92 & 600 & 12 & 50 & $2 \times 5(10)$ & 60 & 8.33 & 15.17 & 16.42 & 17.58 \\
\hline
\end{tabular}
Queensland and New South Wales in 2012 and 2018

a Jiggi orchard surveyed in New South Wales.

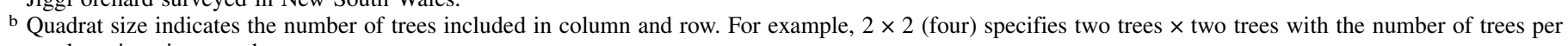
quadrat given in parentheses.

c Significant $\mathrm{z}$ value $(P<0.01)$. 
relationship between $s_{o b s}^{2}$ and $s_{b i n}^{2}$ was described by the binary power law, expressed as

$$
S_{o b s}^{2}=A_{x}\left(S_{b i n}^{2}\right)^{b} \text { where } A_{x}=a n^{b}
$$

$s_{\text {bin }}^{2}=p(1-p) / n$, and $n$ indicates the number of individuals per quadrat (Madden and Hughes 1995). The power law parameters $a$ and $b$ were estimated for each orchard by fitting the linear model to the AVG data of respective orchard using the following linear regression function (Gigot et al. 2017; Hughes and Madden 1992):

$$
\ln \left(s_{o b s}^{2}\right)=\ln (a)+b \ln [p(1-p)]
$$

where $\ln$ indicates the natural $\log$ arithm, and $\ln (a)$ and $b$ denote the intercept and slope of the linear model, respectively. The values
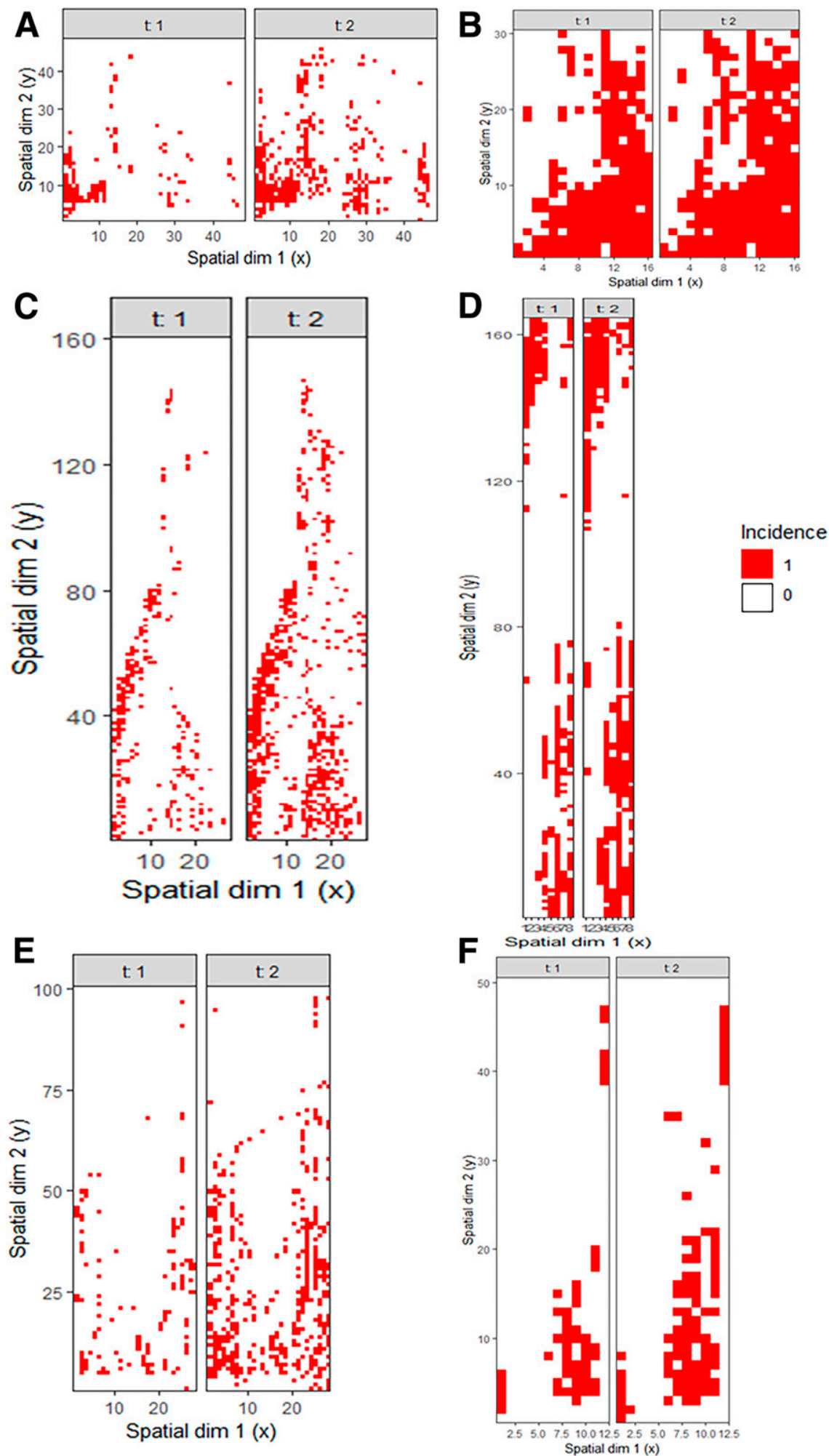

Fig. 2. Spatial distribution of abnormal vertical growth (AVG) incidence in commercial macadamia orchards in Australia in 2012 (t1) and 2018 (t2). A to F, Orchards 1 to 6 , respectively. AVG incidence scale 1 and 0 indicate AVG symptomatic and asymptomatic trees, respectively. The spatial dimension $1(x)$ is the column number and the spatial dimension $2(y)$ is the row number of the trees. 
of $A_{x}$ and $b$ were used to determine the distribution pattern (random or aggregated) of AVG symptomatic trees and the degree of heterogeneity or aggregation. $A_{x}=1$ and $b=1$ indicate a random distribution $\left(s_{o b s}^{2}=s_{b i n}^{2}\right), A_{x}>1$ and $b=1$ indicate an aggregated pattern, but the degree of aggregation or heterogeneity does not change with $p$, whereas $A_{x}>1$ and $b>1$ indicate aggregated incidence and the degree of aggregation depends on $p$ (Madden and Hughes 1995).

Spatial hierarchy analysis. In order to determine the AVG aggregation at individual tree and quadrat level, and to simulate a collection of different AVG incidence dataset in each orchard (Hughes et al. 1997), a spatial hierarchy test was performed with the same orchard-level quadrat sizes used in the power law analyses (Table 2). A "threshold" function was used to characterize each quadrat as AVG "symptomatic" (1) when at least one AVG symptomatic tree was found within the quadrat or "asymptomatic" (0) when no symptomatic trees were found within the quadrat. Tree level was considered as the lowest and quadrat as the highest level of spatial hierarchy in the analysis. A pairwise comparison between the hierarchy levels was performed (Madden and Hughes 1999) and the expected probability of trees with AVG at higher hierarchical level was denoted by $P_{\text {high }}$, whereas $P_{\text {low }}$ represented the probability of symptomatic individual at lower hierarchical level. The effective sample size $(v)$ was calculated using the following complementary log-log (CLL) function between $P_{\text {high }}$ and $P_{\text {low }}$ (Gigot et al. 2017; Hughes and Gottwald 1999; Madden and Hughes 1999):

$$
\ln (v)=\operatorname{CLL}\left(P_{\text {high }}\right)-\operatorname{CLL}\left(P_{\text {low }}\right)
$$

The relative effective sample sizes were calculated by dividing the effective sample size of each orchard by its respective quadrat size.

Geostatistical analysis of large-scale AVG distribution. $S A D I E$ procedure. In order to quantify the spatial patterns of AVG, a widely used two-dimensional geostatistical technique, SADIE
(Gigot et al. 2017; Perry 1995; Perry et al. 1996; Turechek and Madden 1999a) was used. Orchard 1 was analyzed as a representative of all the orchards with respect to distribution patterns (aggregated) of AVG. Spatially referenced trees were used to quantify the spatial arrangement of AVG-affected individuals by computing the distance to regularity, $D_{r}$ (Perry 1995; Perry et al. 1996). In this procedure, an iterative algorithm was used to move the observed locations of individual tree to a regular arrangement and the distance between the observed and the final position of each tree was calculated to quantify the value of $D_{r}$ (Perry et al. 1996). The mean of the distance to regularity of random points in permutations of the pattern $\left(E_{p}\right)$ was used to compute the index of aggregation $\left(I_{a}\right)$ using the following equation:

$$
I_{a}=D_{r} / E_{p}
$$

where $I_{a}>1$ indicates an aggregated spatial pattern, $I_{a}=1$ is indicative of random pattern, and $I_{a}<1$ indicates a regular pattern. Significance of $I_{a}$ was determined by a one-sided spatial randomness test performed from the proportion of randomizations with distance to regularity greater $>D_{r}$ value obtained from the observed dataset (Perry 1995; Perry et al. 1996). Data collected in 2012 and 2018 were analyzed to find the temporal changes in $I_{a}$. The MAPCOMP procedure using the Hellinger distance between the density maps of sampling effort and the recorded intensity data were used to compare the maps of AVG incidence between both years (Gigot 2018; Lavigne et al. 2010).

Spatial autocorrelation and semivariogram. Spatial autocorrelation analysis was done using APE and a semivariogram generated with the "gstat" and "geoR" packages (Paradis and Schliep 2018; Paulo et al. 2018; Pebesma 2004). Second-order spatial autocorrelation analysis was done separately for each orchard to determine the degree of endogenous spatial autocorrelation between adjacent quadrats (Turechek and Madden 1999b). Moran's I was calculated as a measure of spatial autocorrelation using inverse distance matrix. Logit function with the Haldane correction was used to
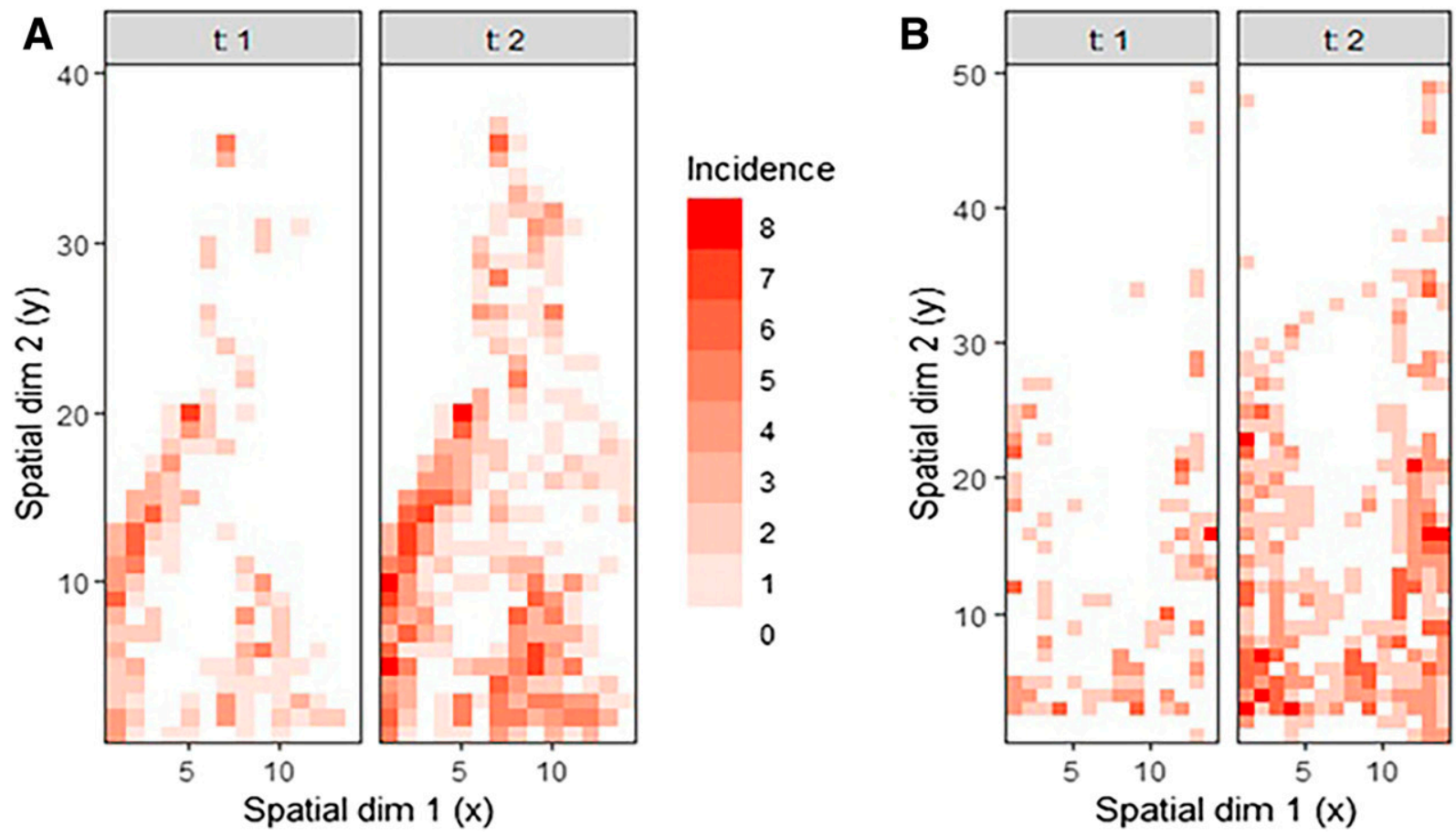

Incidence

Incidence

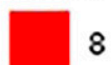

8

6

5

4

3

2

1

0

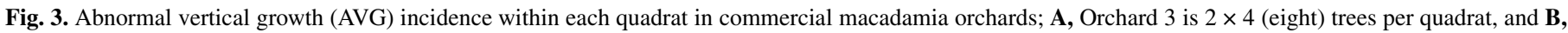

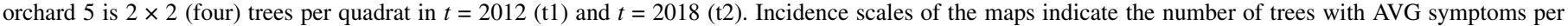
quadrat. Spatial dimension $1(x)$ indicates the $x$-coordinate and spatial dimension $2(y)$ indicates the $y$-coordinate of quadrat. 
stabilize the variance of AVG-affected trees in each quadrat using the formula $y^{\prime}=\ln [y /(1-y)]$, where $y=(N+0.5) /(n+1)$, and $N$ and $n$ are number of AVG-affected and total trees per quadrat, respectively. Semivariance over lag distance and model fitting were performed using "fit.variogram" function of "gstat" software package. A semivariogram was plotted to visualize the spatial autocorrelation of AVG data of each orchard.

\section{RESULTS}

Mapping of AVG incidence. Patterns of AVG in all orchards showed some level of patchiness (aggregation) and the incidence of affected trees clearly increased over the 6-year period (Fig. 2). AVG-affected trees were clustered along one or both (orchard 4) edges of the orchard in $2012(\mathrm{t} 1)$ and became more prevalent toward the middle of the orchard in 2018 (t2) (Fig. 2).

The number of AVG-affected quadrats in all of the orchards increased over time, showing prominent temporal increase of AVG incidence and clustered patterns of AVG-affected trees (Fig. 2). Similarly, the number of AVG-affected trees per quadrat also increased over time in all orchards, indicating clear temporal increase of AVG occurrence (Fig. 3). Among the orchards, the largest number of AVG-affected trees were recorded in orchard 2 with 46.8 and $54.6 \%$ in 2012 and 2018, respectively (Table 1, Fig. 4B).

Spatial pattern of AVG distribution. The $\chi^{2}$ goodness-of-fit and LRS tests for the six orchards revealed that the beta-binomial distribution better described the data than the binomial distribution (Table 3). The maximum likelihood estimates of beta-binomial parameters including the mean AVG incidence $(p)$ and its aggregation parameter $(\theta)$ were consistently higher in 2018 than 2012 in all orchards except orchards 2 and 6 , where the $\theta$ value decreased (Fig. 4). Although different orchards showed different $p$ values, the temporal increase of the AVG incidence across all the orchards remained similar with a median value of $8.5 \%$ over the 6 year period (Fig. 4). The maximum increase of $10.11 \%$ was found in orchard 4, whereas the minimum was recorded in orchard 6 . Orchards 1,2, and 3 showed an increase of $p$ close to the median value while orchards 4 and 5 showed higher values than the median (Fig. 4).

The aggregation parameter $(\theta)$ showed different degrees of heterogeneity among the orchards (Fig. 4). Orchard 2, which
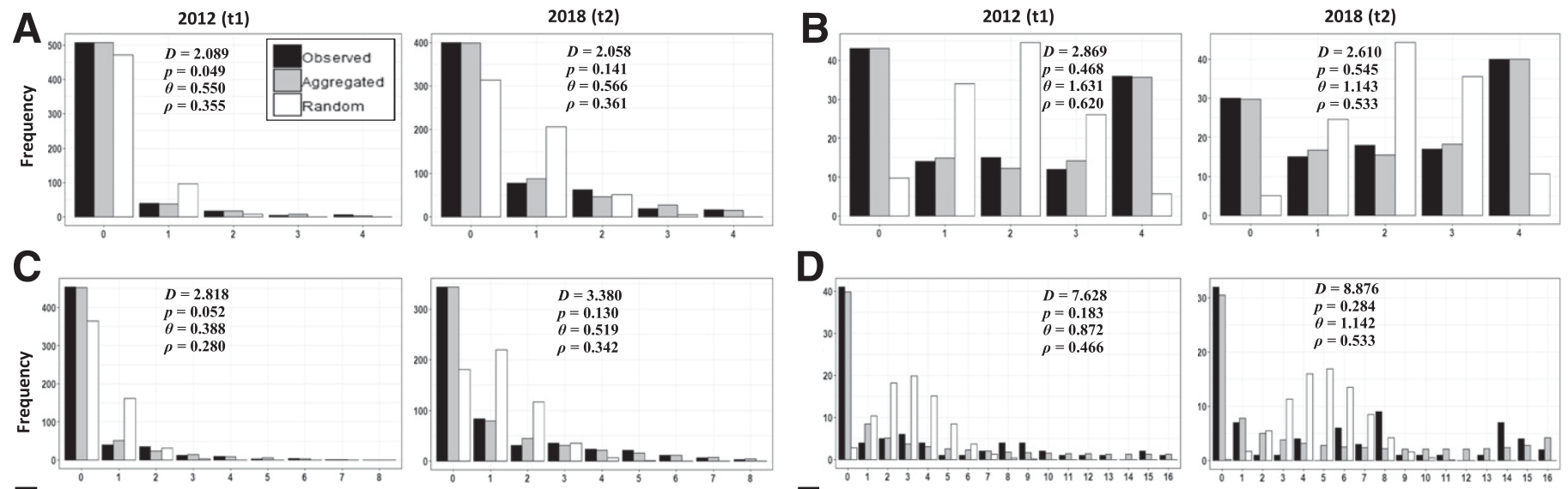

E
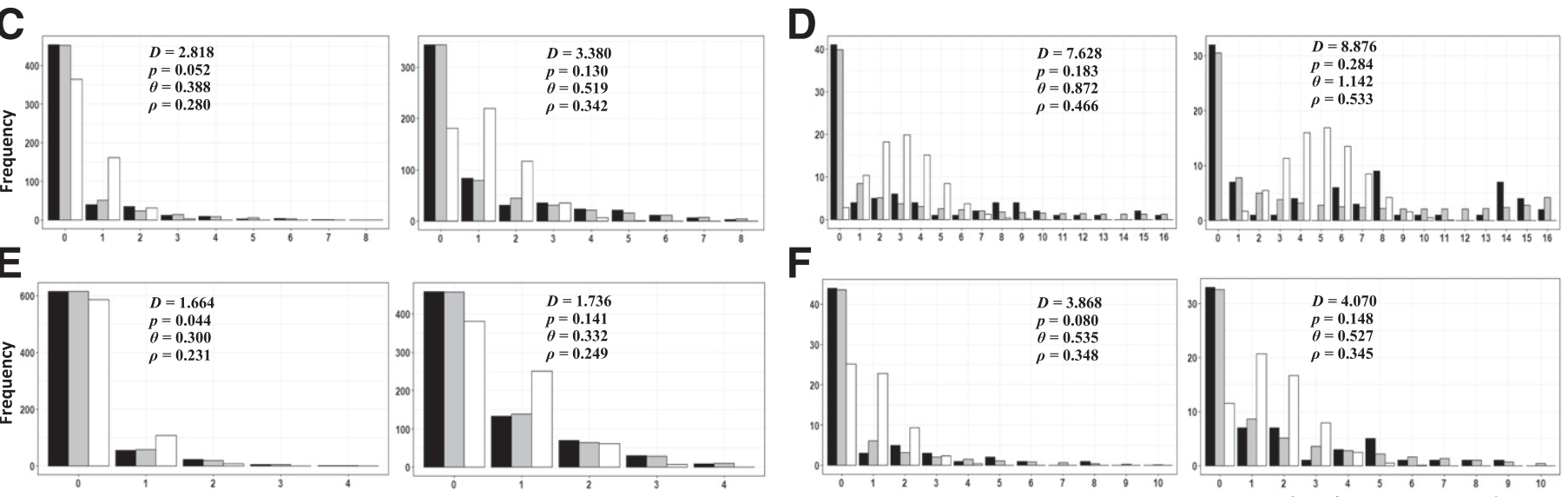

$\mathbf{F}$

Number of AVG trees per quadrat
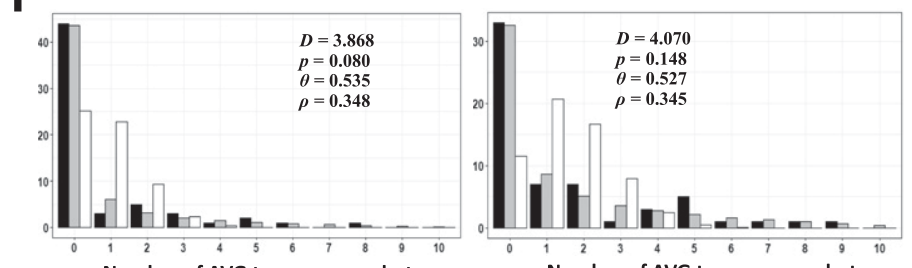

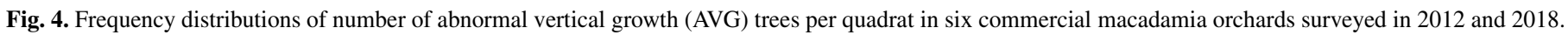

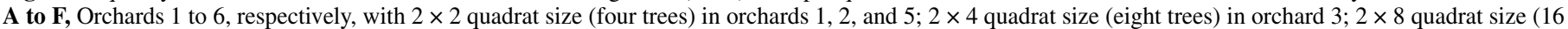

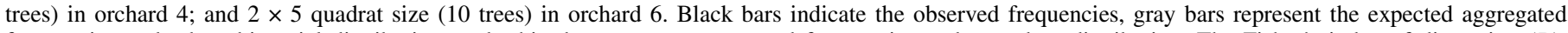

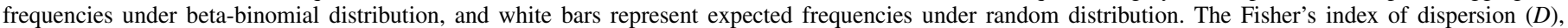

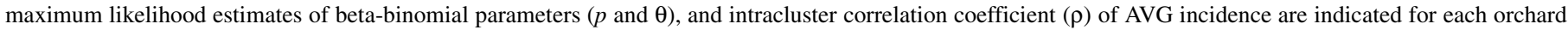
and year.

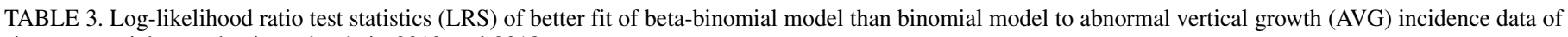
six commercial macadamia orchards in 2012 and 2018

\begin{tabular}{|c|c|c|c|c|c|c|}
\hline \multirow[b]{2}{*}{ Orchard } & \multicolumn{3}{|c|}{ Log-likelihood values for 2012} & \multicolumn{3}{|c|}{ Log-likelihood values for 2018} \\
\hline & Binomial $^{\mathrm{a}}$ & Beta-binomial $^{a}$ & $\mathrm{LRS}^{\mathrm{b}}$ & Binomial $^{\mathrm{a}}$ & Beta-binomial $^{\mathrm{a}}$ & $\mathrm{LRS}^{\mathrm{b}}$ \\
\hline Orchard 1 & 354.66 & 282.28 & 144.76 & 690.10 & 568.12 & 243.97 \\
\hline Orchard 2 & 268.72 & 176.85 & 183.75 & 254.08 & 184.43 & 139.29 \\
\hline Orchard 3 & 599.35 & 433.82 & 331.07 & $1,087.58$ & 751.49 & 672.19 \\
\hline Orchard 4 & 362.03 & 160.23 & 403.58 & 481.60 & 188.03 & 587.15 \\
\hline Orchard 5 & 378.88 & 333.78 & 90.20 & 787.94 & 706.54 & 162.80 \\
\hline Orchard 6 & 106.24 & 66.39 & 79.70 & 147.87 & 95.56 & 104.63 \\
\hline
\end{tabular}

a Values are negative.

b Significant log-likelihood ratio test statistics $(\mathrm{df}=1, P<0.001)$. 
recorded the highest value of $\theta$ in both years, showed a reduction in the value in the 6-year interval between surveys (Fig. 4B), whereas orchard 5 with the lowest $\theta$ values showed an increase over time (Fig. 4E). Aggregation parameters varied in orchards 1, 2, and 5 with the same quadrat size $(2 \times 2)$, showing the heterogeneous nature of $\mathrm{AVG}$ in the quadrats among the orchards.

The intracluster correlation coefficient $(\rho)$ also varied among the orchards (Fig. 4). All orchards showed an increase in the $\rho$ value over time, except orchards 2 and 6 (Fig. 4). These two orchards showed similar trends in the dynamics of $\rho$ and $\theta$ over time (Fig. 4B and F). In 2012, the highest intracluster correlation coefficient $\rho$ value (0.620) was in orchard 2 , whereas the lowest value of 0.231 was in orchard 5. Despite similar quadrat sizes, these two orchards resulted in different $\rho$ values, indicating differences in the withincluster variance. Orchard 2 showed the highest AVG incidence with most of the trees within the quadrats AVG symptomatic, resulting in a low within-cluster variability and higher $\rho$ value. Orchard 2 had the highest reduction (0.087) (Fig. 4B), whereas orchards 3 and 4 showed a similar increase $(>0.06)$ in the $\rho$ values over time (Fig. $4 \mathrm{C}$ and D).

Frequency distribution of number of AVG-affected trees per quadrat revealed that quadrats having one tree with AVG symptoms had similar observed and expected aggregated frequencies in all orchards, except orchard 4 (Fig. 4). Orchard 1 in 2018, and orchards 2 and 5 in both years showed that the observed frequency of AVG trees was similar to the expected aggregated frequency of the same orchard when all the four trees per quadrat $(2 \times 2)$ were symptomatic (Fig. 4A, B, and E). In 2018, where the number of AVG trees observed was $>3$ per quadrat, the observed frequency was mostly similar to the frequency of the aggregated distribution (Fig. 4). Overall, the orchards showed aggregated patterns of AVG-affected trees with different numbers of AVG-affected trees per quadrats.

The Fisher's index of dispersion $(D)$ calculated for all orchards across both years ranged between 1.664 and 8.876 with a median value of 2.844 (Fig. 4). The z-tests showed that $D$ values of all orchards in both years were significantly greater than one $(P<0.01$, Table 1). The highest $D$ value (8.876) was recorded in orchard 4 in both years (Fig. 4D), which had AVG-affected trees at both ends of the orchard (Fig. 2D). Orchard 5, which had the highest degrees of freedom with a quadrat size of four $(2 \times 2)$ trees and was the second largest orchard, exhibited the lowest $D$ values in both years (Fig. $4 \mathrm{E})$. Evaluation of the relationship between $\theta$ and $D$ for both years using orchards 1,2 , and 5 with similar quadrat sizes showed strong $\left(R^{2}>0.96\right)$ linear relationship (Fig. 5A). The relationship between the observed AVG incidence and $D$ showed a slight quadratic relationship (Fig. 5B).
Degree of heterogeneity of AVG incidence. In all orchards, $A_{x}$ value was greater than one. Similarly, the estimates of power law parameter $(b)$ of all the orchards were significantly ( $t$ values given in Figure $6, P<0.05)$ greater than one, whereas the parameter $a$ varied between 0.41 and 0.88 (Fig. 6), suggesting the aggregated patterns of AVG were influenced by the mean of the AVG incidence $(p)$. Orchard 4 had the highest $b$ value (Fig. 6D), whereas the lowest value was showed by orchards 3 and 5 (Fig. 6C and E). The binary form of power law analysis of all orchards showed that most of the cases were close to the linear regression line between the observed

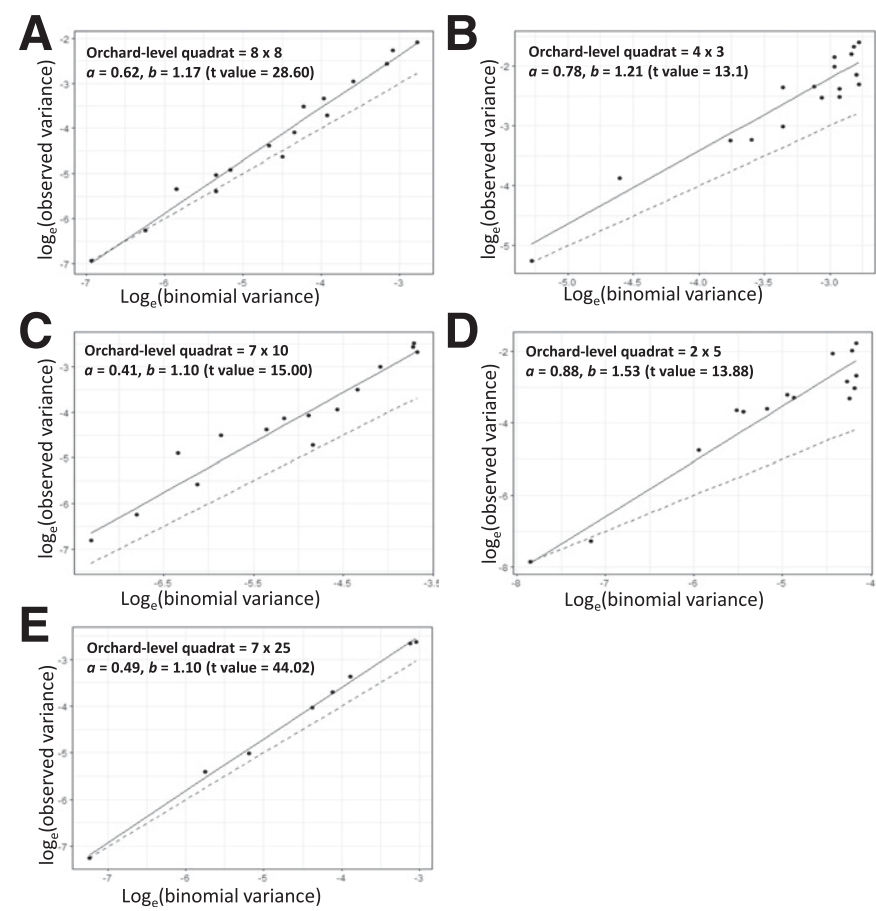

Fig. 6. Relationship between the natural logarithmic values of the observed variance $\left(s_{o b s}^{2}\right)$ and the theoretical variance under binomial distribution $\left(s_{b i n}^{2}\right)$ for abnormal vertical growth (AVG) incidence in $\mathbf{A}$ to $\mathbf{E}$, five commercial macadamia orchards in the Bundaberg region in 2012 and 2018. Solid lines are linear regressions of observed variances and random variances; dashed lines represent equal observed variances and theoretical random variances for random distribution. The larger orchard-level quadrat sizes containing small quadrats of each orchard used in the analysis and the values of binary power law parameters $(a$ and $b$ ) for each orchard are indicated.
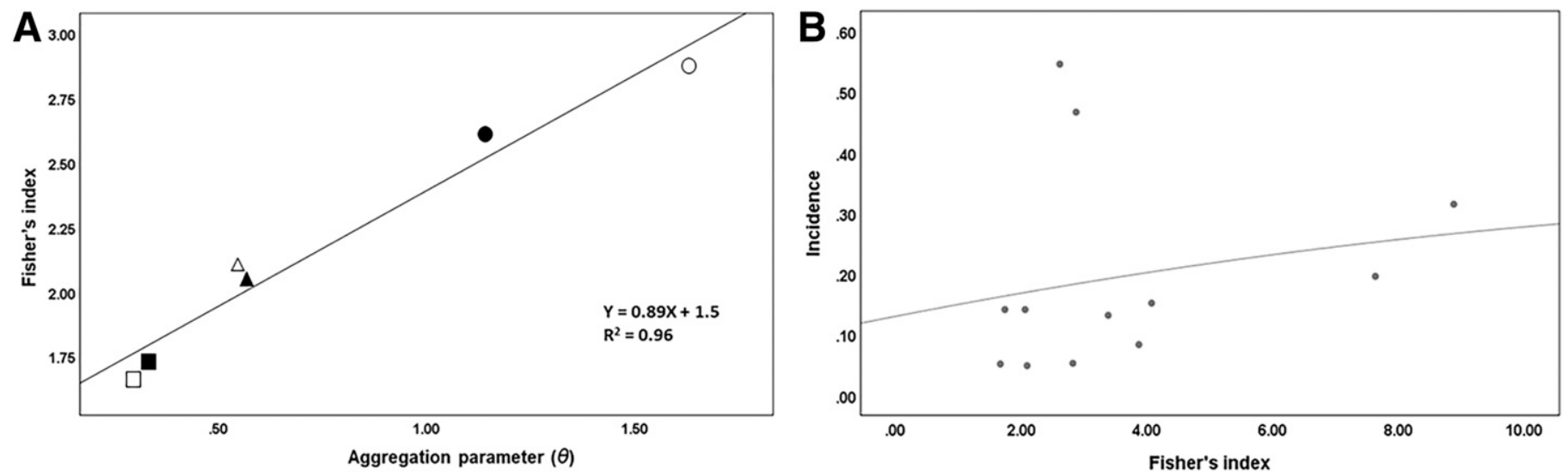

Fig. 5. Relationship between A, the aggregation parameter $(\theta)$ and Fisher's index of dispersion $(D)$ of three commercial macadamia orchards surveyed for abnormal vertical growth $(\mathrm{AVG})$ incidence using similar quadrat size $(2 \times 2)$ in 2012 (hollow points) and 2018 (solid points), and B, observed AVG incidence and Fisher's index of dispersion $(D)$ of six commercial macadamia orchards surveyed in 2012 and 2018. Triangular, circular, and square points represent orchards 1, 2, and 5, respectively. 
and binomial variances (Fig. 6). However, in orchards 1 and 4, few cases showed observed variances equal to the theoretical variances of random distribution (dashed line) (Fig. 2A and D).

Spatial hierarchy analysis. The effective sample sizes $(v)$ for the spatial hierarchy relationship between individual tree and quadrat sizes (4 to 16) ranged between 2.23 and 5.49 in 2012, and 2.15 and 5.76 in 2018 (Table 2). The effective sample sizes of all orchards in both years were lower than their corresponding actual quadrat sizes used in the survey. Among the orchards surveyed in 2012, the highest relative effective sample size (0.81) was exhibited by orchard 5, whereas the lowest (0.33) was by orchard 4. In 2018, the same orchards recorded the highest $(0.77)$ and the lowest $(0.30)$ relative effective sample sizes, respectively.

Geostatistical analysis of large-scale AVG distribution. $S A D I E$ procedure. Based on orchard 1 in both years, $I_{a}$ was greater than one and was significantly different from zero $\left(2012 I_{a}=5.542\right.$; $\left.2018 I_{a}=6.198 ; P<0.01\right)$. The results suggested a clustered (aggregated) pattern of AVG distribution in the orchard in both years. There were two separate clusters of AVG-affected trees in 2012 , with a large cluster covered by four contour lines and a small cluster enclosed by a single contour line at a bandwidth of $h=60$ (Fig. 7A). In 2018, a new cluster with one contour line at the lower right part of the orchard was observed, whereas both clusters observed in 2012 enlarged and merged to form a large cluster with an extension to include some new AVG trees in the upper part of the orchard (Fig. 7B). The large cluster observed in 2018 was formed by the extension of the outermost contour line of the large cluster of 2012 and subsequent enclosure of the small cluster observed in 2012 (Fig. 7). Compared with 2012, there were some AVG-affected trees in the upper right side of the orchard, which did not form part of the clusters (Fig. 7B).

Spatial autocorrelation and semivariogram. All observed Moran's I values were positive (ranged from 0.058 to 0.230 ) in both years, whereas the expected values were negative (ranged from -0.001 to -0.017 ) with significant spatial autocorrelation ( $\mathrm{z}$ values ranged between 7.76 and $67.78, P<0.05$ ). Semivariograms of all orchards in both years showed large range values (ranged from $c a$. 15 to 120), suggesting aggregation of AVG-affected trees beyond the quadrat level (Fig. 8). The shapes of semivariograms with low nugget values confirmed the spatial dependence of AVG in all orchards (Fig. 8). The range of the semivariogram increased over time, explaining the expansion of clusters.

\section{DISCUSSION}

This study provides new epidemiological information for AVG in commercial macadamia orchards in Australia. Our studies revealed highly aggregated patterns of distribution of AVG-affected trees at and above quadrat level, and slow increase in the incidence of disease over a 6-year period. Furthermore, spread of AVG was predominantly over short distances, between neighboring trees in a row or on either side of a row. These observations support the hypothesis that the disease has a biotic etiology, most likely involving a pathogen. An additional argument for a biotic etiology is the fact that AVG occurs in backyard trees, an environment not subject to commercial cultivation practices (O'Farrell et al. 2016).

AVG is an enigmatic syndrome that remains unexplained despite a considerable research effort over 2 decades (O'Farrell et al. 2016). Abiotic factors such as soil type and plant nutrition have been dismissed as a cause of AVG, although water stress (water deficit and waterlogged conditions) appears to trigger the syndrome (Akinsanmi 2017). Searches for an arthropod pest that is consistently associated with the syndrome have been unsuccessful. Our studies revealed the rate of spread of AVG was exceptionally slow, at an average of $2 \%$ increase in incidence of disease per annum. This and the short distance of spread suggest that root grafting or root-to-root contact may therefore be a significant route for the transmission of the infectious agent causing AVG, as is observed with Ceratocystis fagacearum in oak (Blaedow and Juzwik 2010) and avocado sunblotch viroid, Raffaelea lauricola, and Phellinum noxium in avocados (Chung et al. 2015; Ploetz et al. 2016; Schnell et al. 2011). The slow pace at which the epidemic developed is contrary to that expected for pathogens with actively migrating arthropod vectors such as aphids or leafhoppers, or alternatively, pathogens that produce copious amounts of aerially dispersed spores.

The nature of AVG-affected trees and high occurrence in areas with regular extreme environmental conditions (Akinsanmi 2017) allude to a phloem or xylem-restricted pathogen that may be involved in plant hormone modulation. Vascular-limited pathogens
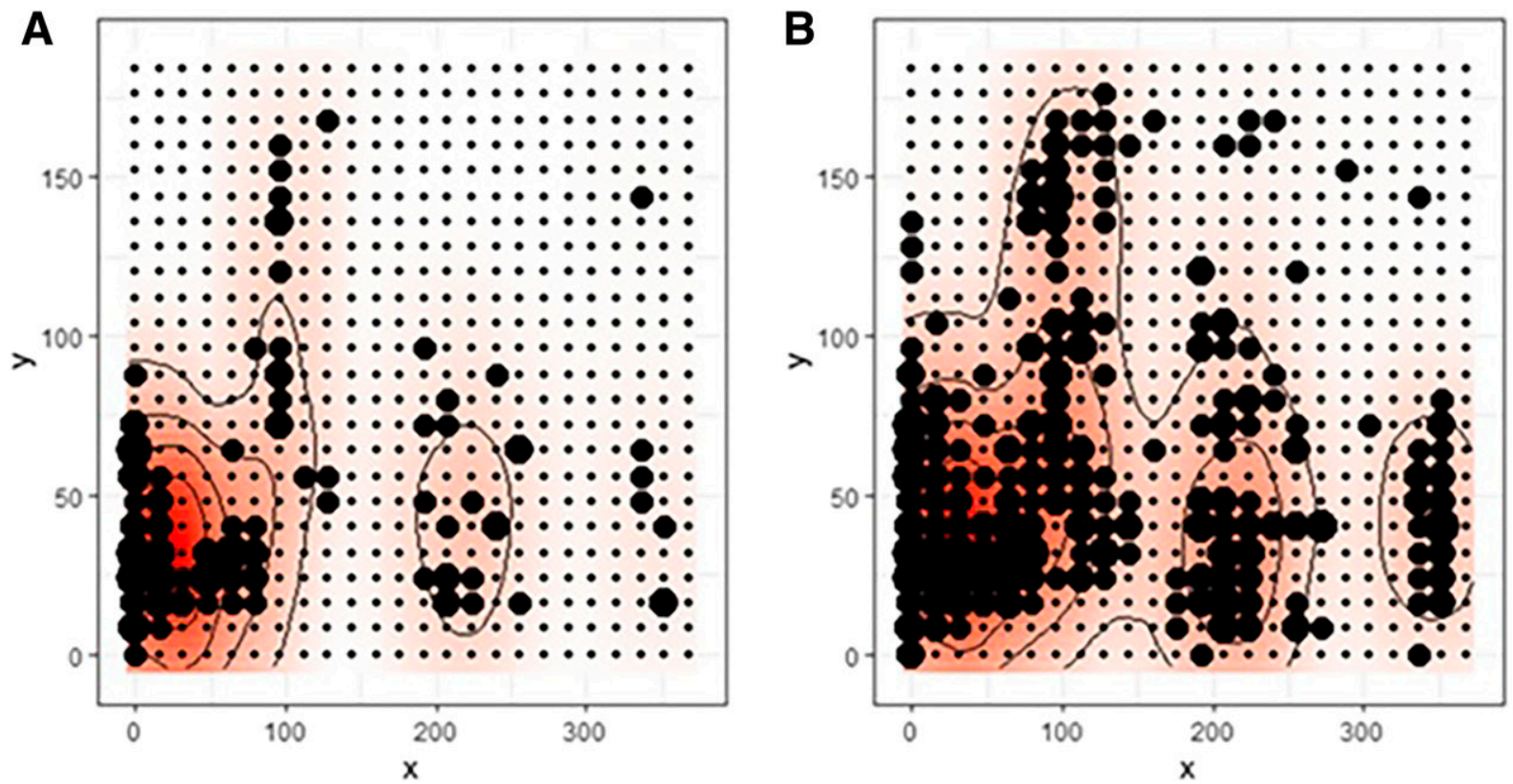

normalized intensity for a bandwidth $h=60$

4e-05

3e-05

2e-05

$1 \mathrm{e}-05$

Fig. 7. Density map of abnormal vertical growth incidence data of orchard 1 in year A, 2012 and B, 2018. Shaded bars show the interpolated landscape of the normalized intensity, and the contours demarcate new clusters. 
such as Candidatus Phytoplasma, Spiroplasma kunkelii, Arsenophonus bacteria, Serratia marcescens, and many viruses have been shown to exhibit aggregated patterns of symptoms with slow development (Beanland et al. 2006; Bendix and Lewis 2018). Higher concentrations of $\mathrm{t}-\mathrm{ZR}$ and $\mathrm{GA}_{3}$ have been detected in AVGaffected macadamia trees compared with asymptomatic trees (Fletcher and Mader 2007). There are many examples of vascular-limited pathogens modulating plant hormone biosynthesis and signaling pathways, including Candidatus Liberibacter, Candidatus Phytoplasma, Spiroplasma citri, and Pseudomonas syringae (Bové and Garnier 2002; Gupta et al. 2017; Hoshi et al. 2009; Mafra et al. 2013; Martinelli et al. 2012; Whitesides and Spotts 1991).

The heterogeneity of plant diseases is mainly attributed to different biological and physical factors at varied spatiotemporal scales (Madden and Hughes 1995; Turechek and Madden 2001). In
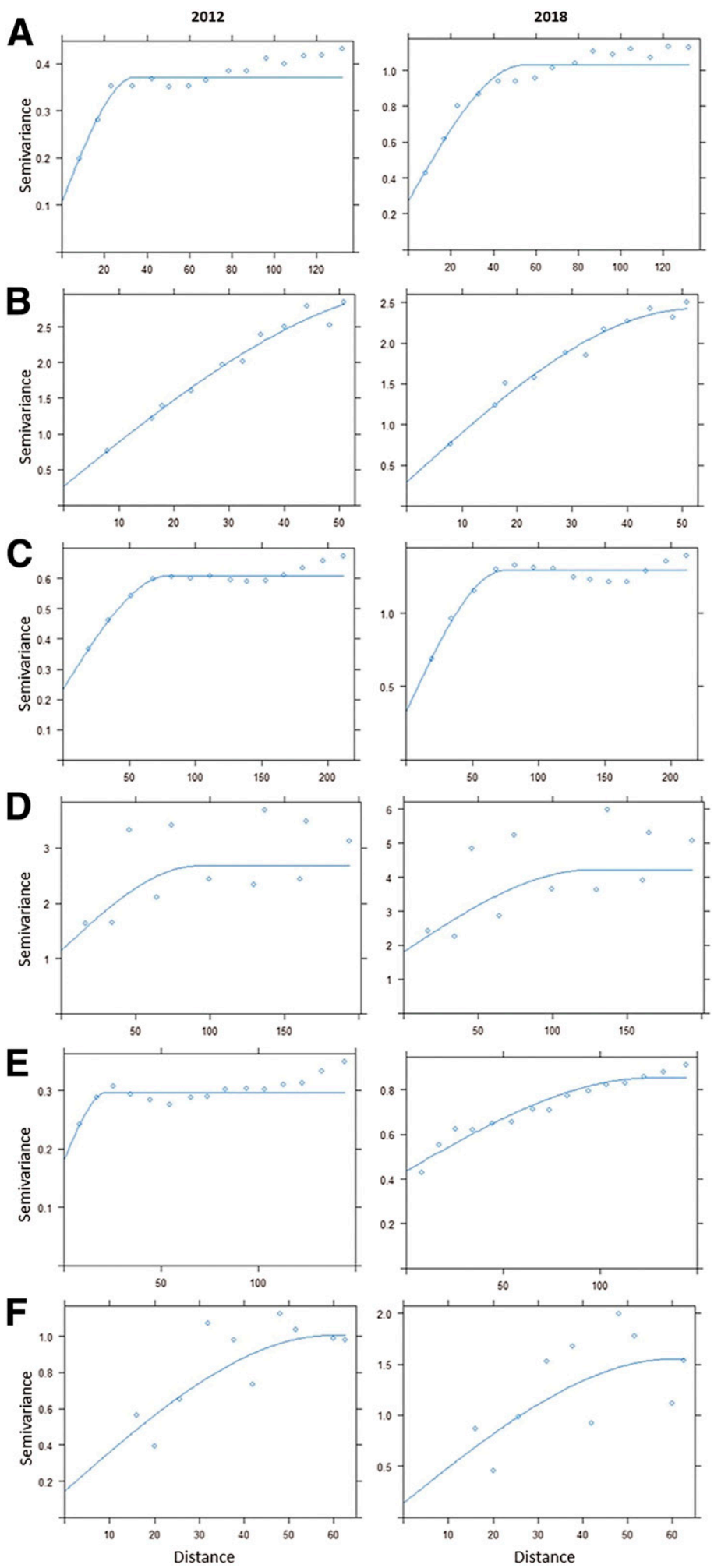

Fig. 8. Semivariograms and fitted models of spatial autocorrelation of abnormal vertical growth-affected macadamia trees in $\mathbf{A}$ to $\mathbf{F}$, orchards 1 to 6 in 2012 and 2018. 
the present study, the influence of interplanting of susceptible (Hawaiian) cultivars with mostly tolerant (Australian) cultivars on the spread of AVG could have contributed to the heterogeneity observed in AVG incidence among the orchards. In most orchards, two or more cultivars are planted in the same block to improve the cross-pollination rates to enhance fruit set (O'Hare et al. 2004). Different combinations of Australian and Hawaiian cultivars planted in each orchard may have contributed to the varied heterogeneity of AVG incidence among the orchards. In orchards with many aggregated clusters, the intracluster correlation coefficient $\rho$ was high, which resulted in low within-cluster variability. Therefore, the greatest impact of AVG in reducing orchard productivity will occur in small orchards.

The large-scale geostatistical analyses with SADIE, spatial autocorrelation analysis, and semivariogram confirmed the spatial dependence and aggregation of AVG-affected trees at and beyond quadrat level, and the expansion of AVG aggregation over time. This is clear evidence to show that the AVG incidence increased over time. In conclusion, all analyses indicate that AVG incidence in the orchards was aggregated and showed temporal increase, providing a clue that the cause is pathogenic. While clear patterns exist and spread appears localized, more research is underway to test the hypothesis of a biotic etiology for AVG.

\section{ACKNOWLEDGMENTS}

M. C. M. Zakeel acknowledges the Australian Commonwealth Government Research Training Programme (RTP) scholarship. We thank Chris Searle (macadamia consultant) and Lindsay Bryen for access to information and orchards; Vincent Mellor for his advice on statistical analysis; and Chris Gilligan, University of Cambridge, for his feedback on the manuscript.

\section{LITERATURE CITED}

Akinsanmi, O. A. 2017. Determining the extent and causes of abnormal vertical growth. Final report for project MC15011-Sydney. Horticulture Innovation Australia, Ltd.,Sydney.

Akinsanmi, O. A., and Drenth, A. 2017. Characterisation of husk rot in macadamia. Ann. Appl. Biol. 170:104-115.

Akinsanmi, O. A., Neal, J., Drenth, A., and Topp, B. 2017. Characterization of accessions and species of Macadamia to stem infection by Phytophthora cinnamomi. Plant Pathol. 66:186-193.

Beanland, L., Noble, R., and Wolf, T. K. 2006. Spatial and temporal distribution of North American grapevine yellows disease and of potential vectors of the causal phytoplasmas in Virginia. Environ. Entomol. 35:332-344.

Beilharz, V., Mayers, P. E., and Pascoe, I. G. 2003. Pseudocercospora macadamiae sp. nov., the cause of husk spot of macadamia. Australas. Plant Pathol. 32:279.

Bendix, C., and Lewis, J. D. 2018. The enemy within: Phloem-limited pathogens. Mol. Plant Pathol. 19:238-254.

Blaedow, R. A., and Juzwik, J. 2010. Spatial and temporal distribution of Ceratocystis fagacearum in roots and root grafts of oak wilt affected red oaks. Arboric. Urban For. 36:28-34.

Bové, J., and Garnier, M. 2002. Phloem-and xylem-restricted plant pathogenic bacteria. Plant Sci. 163:1083-1098.

Chung, C.-L., Huang, S.-Y., Huang, Y.-C., Tzean, S.-S., Ann, P.-J., Tsai, J.-N., Yang, C.-C., Lee, H.-H., Huang, T.-W., and Huang, H.-Y. 2015. The genetic structure of Phellinus noxius and dissemination pattern of brown root rot disease in Taiwan. PLoS One 10:e0139445.

Fletcher, A., and Mader, J. 2007. Hormone profiling by LC-QToF-MS/MS in dormant Macadamia integrifolia: Correlations with abnormal vertical growth. J. Plant Growth Regul. 26:351-361.

Fletcher, A. T., and Mader, J. C. 2011. A report of the morphology and hormone content of AVG macadamia. Horticulture Australia Ltd., Sydney.

Garg, M. L., Blake, R. J., Wills, R. B. H., and Clayton, E. H. 2007. Macadamia nut consumption modulates favourably risk factors for coronary artery disease in hypercholesterolemic subjects. Lipids 42:583-587.

Gigot, C. 2018. Analyzing plant disease epidemics with the R package epiphy. https://cran.r-project.org/web/packages/epiphy/vignettes/epiphy.html

Gigot, C., Turechek, W., and McRoberts, N. 2017. Analysis of the spatial pattern of strawberry angular leaf spot in California nursery production. Phytopathology 107:1243-1255.

Gottwald, T., Cambra, M., Moreno, P., Camarasa, E., and Piquer, J. 1996. Spatial and temporal analyses of citrus tristeza virus in eastern Spain. Phytopathology 86:45-55.
Griel, A. E., Cao, Y., Bagshaw, D. D., Cifelli, A. M., Holub, B., and Kris-Etherton, P. M. 2008. A macadamia nut-rich diet reduces total and LDL-cholesterol in mildly hypercholesterolemic men and women. J. Nutr. 138:761-767.

Gupta, A., Hisano, H., Hojo, Y., Matsuura, T., Ikeda, Y., Mori, I. C., and Senthil-Kumar, M. 2017. Global profiling of phytohormone dynamics during combined drought and pathogen stress in Arabidopsis thaliana reveals ABA and JA as major regulators. Sci. Rep. 7:4017.

Hamilton, R. A., Ito, P. J., and Chia, C. L. 1983. Macadamia: Hawaii's dessert nut. University of Hawaii, College of Tropical Agriculture and Human Resources, Hawaii.

Hoshi, A., Oshima, K., Kakizawa, S., Ishii, Y., Ozeki, J., Hashimoto, M., Komatsu, K., Kagiwada, S., Yamaji, Y., and Namba, S. 2009. A unique virulence factor for proliferation and dwarfism in plants identified from a phytopathogenic bacterium. Proc. Natl. Acad. Sci. 106:6416-6421.

Hughes, G., and Gottwald, T. 1999. Survey methods for assessment of citrus tristeza virus incidence when Toxoptera citricida is the predominant vector. Phytopathology 89:487-494.

Hughes, G., and Madden, L. 1992. Aggregation and incidence of disease. Plant Pathol. 41:657-660.

Hughes, G., and Madden, L. 1993. Using the beta-binomial distribution to describe aggregated patterns of disease incidence. Phytopathology 83: 759-763.

Hughes, G., McRoberts, N., Madden, L., and Gottwald, T. 1997. Relationships between disease incidence at two levels in a spatial hierarchy. Phytopathology 87:542-550.

Jones, V., Follett, P., Westcot, D., and Campora, C. 1996. Developing management alternatives for the tropical nut borer, Hypothenemus obscurus. Pages 23-33 in: 36th Annual conference proceedings Hawaii Macadamia Nut Association, University of Hawaii, Hilo.

Jones, V. P. 1994. Feeding by Cryptophlebia illepida and C. ombrodelta (Lepidoptera: Tortricidae) on macadamia nut abortion. J. Econ. Entomol. 87:781-786.

Jones, V. P., Westcott, D. M., Finson, N. N., and Nishimoto, R. K. 2001. Relationship between community structure and southern green stink bug (Heteroptera: Pentatomidae) damage in macadamia nuts. Environ. Entomol. 30:1028-1035.

Lavigne, C., Ricci, B., Franck, P., and Senoussi, R. 2010. Spatial analyses of ecological count data: A density map comparison approach. Basic Appl. Ecol. 11:734-742.

Madden, L., and Hughes, G. 1995. Plant disease incidence: Distributions, heterogeneity, and temporal analysis. Annu. Rev. Phytopathol. 33:529-564.

Madden, L., and Hughes, G. 1999. An effective sample size for predicting plant disease incidence in a spatial hierarchy. Phytopathology 89:770-781.

Mafra, V., Martins, P. K., Francisco, C. S., Ribeiro-Alves, M., Freitas-Astúa, J., and Machado, M. A. 2013. Candidatus Liberibacter americanus induces significant reprogramming of the transcriptome of the susceptible citrus genotype. BMC Genomics 14:247.

Mak, T. K. 1988. Analyzing intraclass correlation for dichotomous variables. J. R. Stat. Soc. Ser. C Appl. Stat. 37:344-352.

Martinelli, F., Uratsu, S. L., Albrecht, U., Reagan, R. L., Phu, M. L., Britton, M., Buffalo, V., Fass, J., Leicht, E., and Zhao, W. 2012. Transcriptome profiling of citrus fruit response to huanglongbing disease. PLoS One 7: e38039.

Nock, C. J., Hardner, C. M., Montenegro, J. D., Ahmad Termizi, A. A., Hayashi, S., Playford, J., Edwards, D., and Batley, J. 2019. Wild origins of macadamia domestication identified through intraspecific chloroplast genome sequencing. Front. Plant Sci. 10:334.

O'Farrell, P. 2011. Developing corrective treatments for maintaining macadamia nut production and normal growth. MC03012 Project Final Report, Horticulture Australia, Sydney.

O'Farrell, P., Le Lagadec, D., and Searle, C. 2016. 'Abnormal vertical growth': A disorder threatening the viability of the Australian macadamia industry. Acta Hortic. 1109:143-150.

O'Farrell, P., and Searle, C. 2003. 'Abnormal vertical growth' disorder of macadamia (Macadamia integrifolia) - A discussion of potential causes. Horticulture Australia Ltd., Sydney.

O'Hare, P., Quinlan, K., Stephenson, R. A., and Vock, N. 2004. Macadamia grower's handbook: Growing guide. Department of Primary Industries, Queensland, Australia.

Paradis, E., and Schliep, K. 2018. ape 5.0: An environment for modern phylogenetics and evolutionary analyses in R. Bioinformatics 35:526-528.

Paulo, J., Ribeiro, J., and Peter, J. D. 2018. geoR: Analysis of Geostatistical Data. R package version 1.7-5.2.1.

Peace, C., Hardner, C., and Nock, C. 2017. Genetic origins of macadamia cultivars: What we know so far. in: 2017 International Macadamia Research Symposium, Big Island, Hawaii.

Pebesma, E. J. 2004. Multivariable geostatistics in S: The gstat package. Comput. Geosci. 30:683-691. 
Perry, J., Bell, E., Smith, R., and Woiwod, I. 1996. SADIE: Software to measure and model spatial pattern. Asp. Appl. Biol. 46:95-102.

Perry, J. N. 1995. Spatial analysis by distance indices. J. Anim. Ecol. 64: 303-314.

Ploetz, R., Hughes, M., Kendra, P., Fraedrich, S., Carrillo, D., Stelinski, L., Hulcr, J., Mayfield, A., III, Dreaden, T., and Crane, J. 2016. Recovery plan for laurel wilt of avocado, caused by Raffaelea lauricola. Plant Health Prog. 18:51-77.

R Development Core Team. 2013. R: A language and environment for statistical computing. R Foundation for Statistical Computing, Vienna.

Schnell, R. J., Tondo, C. L., Kuhn, D. N., Winterstein, M. C., Ayala-Silva, T., and Moore, J. M. 2011. Spatial analysis of avocado sunblotch disease in an avocado germplasm collection. J. Phytopathol. 159:773-781.

Stephenson, R. 2005. Macadamia: Domestication and commercialization. Chron. Hortic. 45:11-15.

Stephenson, R., Cox, J., Searle, C., Moody, P., Pattison, T., Cobon, J., O'Farrell, P., and Van Zwieten, L. 2004. Develop a benchmark for soil health in macadamia orchards. Horticulture Australia Ltd., Sydney.
Turechek, W., Ellis, M., and Madden, L. 2001. Sequential sampling for incidence of Phomopsis leaf blight of strawberry. Phytopathology 91:336-347.

Turechek, W., and Madden, L. 1999a. Spatial pattern analysis and sequential sampling for the incidence of leaf spot on strawberry in Ohio. Plant Dis. 83: 992-1000.

Turechek, W., and Madden, L. 1999b. Spatial pattern analysis of strawberry leaf blight in perennial production systems. Phytopathology 89:421-433.

Turechek, W. W., and Madden, L. V. 2001. Effect of scale on plant disease incidence and heterogeneity in a spatial hierarchy. Ecol. Modell. 144:77-95.

Turechek, W. W., and Mahaffee, W. F. 2004. Spatial pattern analysis of hop powdery mildew in the Pacific Northwest: Implications for sampling. Phytopathology 94:1116-1128.

Wallace, H. M., and Walton, D. A. 2011. Macadamia (Macadamia integrifolia, Macadamia tetraphylla and hybrids). Pages 450-474 in: Postharvest Biology and Technology of Tropical and Subtropical Fruits. E. M. Yahia, ed. Woodhead Publishing.

Whitesides, S., and Spotts, R. 1991. Frequency, distribution, and characteristics of endophytic Pseudomonas syringae in pear trees. Phytopathology 81:453-457. 